\title{
Role of the short stay observation ward in accident and emergency departments in the United Kingdom
}

\author{
S W Goodacre
}

\begin{abstract}
Objective-To define the role of the accident and emergency (A\&E) short stay ward by a survey of departments in the United Kingdom and review of published reports.
\end{abstract}

Methods-A postal questionnaire with telephone follow up to all major $A \& E$ departments with short stay beds.

Results-95 departments were found to have short stay beds. These units received between 19000 and 121000 new patients per year (mean 51 000, median 50 500) and had access to between two and 20 beds (mean 7.5, median 6). The level of provision varied from one bed per 2440 new attendances to one bed per 27250 new attendances (mean 8380, median 6625). Where data on admission rates were available the departments admitted between $0.1 \%$ and $13.3 \%$ of their new attendances (mean $2.62 \%$, median $1.9 \%$ ). Cover was typically provided by an A\&E senior house officer with frequent senior ward rounds. While the casemix usually included minor head injuries and alcohol intoxicated patients, there was considerable variation in the cases admitted.

Conclusions-Short stay provision is highly variable in the United Kingdom. While there are many reports of well run short stay units, consistent evidence of clinical value and cost-effectiveness compared to other methods of care is lacking. Further comparative studies are required to define the role of the $A \& E$ short stay ward.

( $F$ Accid Emerg Med 1998;15:26-30)

Keywords: short stay ward; observation ward

The provision of short stay observation beds has been a constant feature of recommendations regarding the development of accident and emergency (A\&E) facilities. ${ }^{1-4}$ While attempts have been made to quantify the number of beds available to $A \& E$ departments of different sizes, ${ }^{25}$ there have been few consistent guidelines relating to practical issues, such as which cases should be admitted and what level of medical cover should be provided.

The aim of this study was to define the role of the short stay ward or observation unit by survey of the use A\&E short stay facilities in the United Kingdom and review of the literature to determine the extent to which their use is supported by research.

\section{Methods}

A questionnaire (fig 1) was sent to the clinical director or first named consultant of all 114 A\&E departments listed in the British Association for Accident and Emergency Medicine (BAEM) 1996 directory $^{6}$ as having short stay beds. If no reply was received within six weeks the information was collected by telephone call to the department. The 146 remaining major units listed in the directory were contacted by telephone to ascertain if they had short stay beds and were sent a questionnaire if the answer was affirmative.

\section{Results}

Postal replies were obtained from 80 of the 114 departments initially surveyed $(70 \%)$. Data were collected by telephone from the remaining 34 departments (overall 100\% response rate). In 26 cases the response indicated that there were no short stay beds and these were therefore excluded from further analysis. Although we did not specifically ask why there were no short stay beds in these departments in spite of their listing in the BAEM handbook, various reasons were nevertheless volunteered: closure due to economic reasons, redevelopment of facilities, or facilities referred to in the BAEM handbook as being admissions units not under the control of the A\&E department.

Telephone survey of departments not listed as having short stay beds in the BAEM directory detected seven further departments with beds. These were sent the questionnaire and replies obtained.

In total, therefore, 95 of the major $A \& E$ units surveyed have short stay beds. These departments received between 19000 and 121000 new attendances per year with a mean of 51000 and median of 50500 . While 10 had unlimited bed access, the others had between two and 20 beds (mean 7.5, median 6). For these 85 units, the number of attendances per bed varied from 2440 to 27250 (mean 8380 , median 6625).

Table 1 outlines the first on call medical cover for short stay patients. Table 2 identifies the clinical staff who performed ward rounds, while table 3 shows how often such ward rounds were undertaken. Table 4 outlines the type of patients cared for on short stay wards. Numerous other categories of patient were mentioned as being routinely admitted, but with the exception of minor burns (cited in four responses) none was cited in more than two responses.

Information on admission rates was available from 74 departments $(78 \%)$; the number of 
I am carrying out a review of accident and emergency short stay/observation facilities in the UK and would be very grateful if you or a member of your staff could spare a minute to answer the following simple questions regarding your department.

1 How many short stay/observation beds does your department have access to? -if none, please ignore the remaining questions.

2 Who is first on-call for patients in these beds?

3 How many times per day are ward rounds carried out? -and by whom?

4 Which categories of patient are routinely admitted?

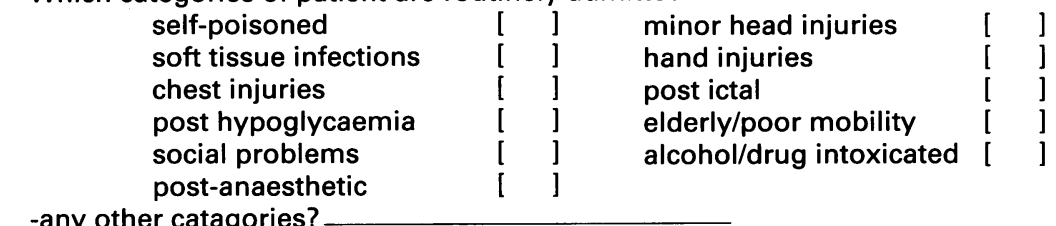
-any other catagories?

5 How many patients were admitted to these beds in the last year?

6 What is the occupancy rate for these beds? (if numbers are available)

It is intended that the results of this survey will provide a national picture of short stay bed use. Individual hospital responses will not be reported.

Thank you once again for your help with this project.

Figure 1 Questionnaire used to survey short stay facilities.

Table 1 Medical staff first on call for short stay

\begin{tabular}{lrl}
\hline All A\&E staff & 6 & $(6.3 \%)$ \\
A\&E consultant & 6 & $(6.3 \%)$ \\
A\&E registrar & 4 & $(4.2 \%)$ \\
A\&E "senior staff" & 5 & $(5.3 \%)$ \\
A\&E staff grade & 3 & $(3.2 \%)$ \\
A\&E senior house officer & 66 & $(69.5 \%)$ \\
Orthopaedic SHO & 2 & $(2.1 \%)$ \\
Surgical SHO & 2 & $(2.1 \%)$ \\
No response & 1 & $(1.0 \%)$ \\
\hline
\end{tabular}

admissions varied from 70 to 6925 per year (mean 1318, median 940). This represents an admission rate ranging from $0.1 \%$ to $13.3 \%$ of attendances (mean $2.62 \%$, median $1.9 \%$ ). The responses regarding bed occupancy rate were not adequate for analysis.

Table 2 Medical staff performing ward rounds

A\&E consultant $47(49.5 \%)$ A\&E registrar $3(3.2 \%)$ $\mathrm{A} \& \mathrm{E}$ "senior

staff" A\&E staff grade $\quad 3(3.2 \%)$ No response $2(2.1 \%)$

Table 3 Number of ward rounds per day

\begin{tabular}{lrl}
\hline One & 54 & $(56.8 \%)$ \\
One to two & 12 & $(12.6 \%)$ \\
Two & 22 & $(23.2 \%)$ \\
Two to three & 1 & $(1.0 \%)$ \\
Three & 1 & $(1.0 \%)$ \\
As required & 5 & $(5.3 \%)$ \\
\hline
\end{tabular}

\section{Discussion}

The A\&E short stay ward has been described as "essential for the good and safe management of patients" in a leading textbook. ${ }^{7}$ Guidelines from the British Association of Accident and Emergency Medicine s $^{5}$ state that it is "an essential part of every accident and emergency department" and suggest provision of one bed per 5000 new attendances. This survey shows that departments with such facilities (a minority of all departments) provide an average of one bed per 8370 new attendances. The guidelines do not cover the issue of casemix, and our survey shows that, with the exception of head injured or alcohol intoxicated patients, the casemix of patients routinely admitted to short stay wards is varied. What then is the evidence base for short stay provision and what should be the role of the short stay ward?

To answer this question a computer search of Medline (1966 to 1996) and CINAHL (1982 to 1996) was undertaken, searching for the textwords "short stay," "observation ward," or "observation unit." In addition, the textword "observation" was searched for in any article with the medical subheading "emergency services/hospital," "emergencies," "hospitalisation," or "patient admission." All articles analysing the function of an $A \& E$ (or emergency department) based short stay ward were reviewed. Paediatric short stay provision has been surveyed ${ }^{8}$ and reviewed ${ }^{9}$ elsewhere, so only studies relating to adult short stay facilities were sought.

Table 4 Casemix of short stay ward admissions

\begin{tabular}{lll}
\hline Minor head injury & 85 & $(89 \%)$ \\
Alcohol/drug intoxicated & 76 & $(80 \%)$ \\
Elderly/poor mobility & 66 & $(69 \%)$ \\
Social problems & 64 & $(67 \%)$ \\
Soft tissue infection & 62 & $(65 \%)$ \\
Self poisoned & 54 & $(57 \%)$ \\
Postictal & 52 & $(55 \%)$ \\
Postanaesthetic & 46 & $(48 \%)$ \\
Chest injury & 42 & $(44 \%)$ \\
Post-hypoglycaemia & 37 & $(39 \%)$ \\
Hand injury & 34 & $(36 \%)$
\end{tabular}

Defined as the number (and percentage) of wards out of the total of 95 which routinely admit each category of patient. 
Table 5 General descriptive studies of short stay ward function

\begin{tabular}{lllllll}
\hline Author & Date & Location & Cases studied & Beds & Admissions & $\begin{array}{l}\% \text { of } \\
\text { Attendances }\end{array}$ \\
\hline Rainer & 1996 & Glasgow, UK & Various & 32 & 2460 in 1 year & $3.3 \%$ \\
Jones & 1995 & Liverpool, UK & Various & 18 & 1833 in 6 months & $4.36 \%$ \\
Maimaris & 1991 & London, UK & Various & 13 & 1046 in 1 year & $2.1 \%$ \\
Jelinek & 1989 & Fremantle, Aus & Various & 8 & 1219 in 1 year & $1.5 \%$ \\
Clancy & 1989 & Leeds, UK & Various & 16 & 1067 in 1 year & $1.4 \%$ \\
Driscoll & 1987 & Glasgow, UK & Various & 16 & 1000 consecutive & N/R \\
Gabbay & 1987 & London, UK & Various & 10 & 3097 in 1 year & N/R \\
Neville & 1983 & Saskatoon, Can & Various & 8 & 1000 per year & $1.3 \%$ \\
Ramaiah & 1982 & Clywd, UK & "Observation" & 12 & 431 in 6 months & N/R \\
Dallos & 1981 & London, UK & Various & 12 & 1070 in 6 months & $1.6 \%$ \\
& & Enfield, UK & Various & 10 & 369 in 6 months & $1.1 \%$ \\
Morgan & 1981 & Newport, UK & Various & 10 & 507 in 3 months & $5 \%$ \\
Bobzien & 1979 & N Carolina, USA & Various & 4 & 442 in 5 months & $4.7 \%$ \\
Diamond & 1976 & Torrance, USA & Various & 8 & 166 in 1 month & $2 \%$ \\
Landers & 1975 & Kansas, USA & Various & 7 & 1000 in 10 months & $2.3 \%$ \\
Taubenhaus & 1972 & Manhatten, USA & Various & N/R & N/R & $5.4 \%$ \\
\hline
\end{tabular}

The search found many descriptive studies of the general function of $A \& E$ short stay wards. ${ }^{10-24}$ These reports, outlined in table 5, form the basis of the BAEM guidelines. Their conclusions are generally favourable, based on demonstration of effective, well run units, and reflect the authors' enthusiasm for this form of care. However, in a health care system which demands evidence of clinical value and costeffectiveness before resources are allocated, it is perhaps not surprising that descriptive studies have not provided incontrovertible evidence of the value of short stay beds for their provision to be universal.

Other studies, ${ }^{11}{ }^{25-37}$ outlined in table 6 , have concentrated on the management of specific conditions on the short stay ward and could provide guidance as to an appropriate casemix. Patients with head injuries, ${ }^{11} 2628$ thoracic trauma with normal chest $x$ ray, ${ }^{35}$ abdominal trauma with negative diagnostic peritoneal lavage, ${ }^{32}$ self harm, ${ }^{25} 29{ }^{34}$ pyelonephritis, ${ }^{3031}$ asthma ${ }^{27}$ and pancreatitis ${ }^{33}$ can all be cared for on a short stay ward. Although these studies describe safe and effective management of various conditions on the short stay ward, it is only by comparison with other methods of care or analysis of cost-effectiveness that the importance of the short stay ward can be established.

Comparative studies have been used to evaluate the impact that access to a short stay ward has upon the care of head injured patients, by comparison with another hospital lacking such a facility ${ }^{26}$ and by comparison with a period of time when the ward was closed. ${ }^{28}$ Both found that fewer inappropriate discharges occurred when short stay facilities where available. Nevertheless, debate arose as to whether admissions represented an appropriately careful approach, ${ }^{11}$ application of overcautious guidelines, ${ }^{26}{ }^{28}$ or whether a lower threshold for computerised tomography would obviate the need for admission altogether for many cases. $^{38}$. Another comparative study involving a variety of cases showed that short stay patients received earlier senior medical review, fewer investigations, and earlier discharge..$^{39}$ This study, although opportunistic and therefore poorly controlled, suggests that comparison of $A \& E$ short stay management with formal admission deserves more consideration. Meanwhile in the USA, two studies into chronic pancreatitis ${ }^{33}$ and asthma ${ }^{27}$ compared observation units with formal hospital admission and showed no advantage in terms of reducing length of stay and reducing costs. The study of asthmatics also showed a lower initial discharge rate from the emergency department when the observation unit was available. As with head injuries, the presence of a short stay facility may encourage a more cautious approach to patient discharge.

Several studies have assessed the costeffectiveness of short stay wards. Ryan et $a^{25}$ estimated that short stay care of self harmed

Table 6 Studies of specific cases managed on the short stay ward (SSW)

\begin{tabular}{|c|c|c|c|c|}
\hline Author & Date & Location & Cases studied & Conclusions \\
\hline Ryan & 1996 & Brighton UK & Self harm & Most self harmed patients can be safely managed on an SSW \\
\hline Jones & 1995 & Liverpool UK & Various/head injured & The SSW is essential for the optimal management of the head injured patient \\
\hline Brown & 1994 & Edinburgh UK & Head injured & $\begin{array}{l}\text { Fewer head injured patients are discharged from A\&E if the department has } \\
\text { access to an SSW }\end{array}$ \\
\hline Brillman & 1994 & New Mexico USA & Asthma & $\begin{array}{l}\text { Use of observation unit reduces initial discharge rate without reducing eventual } \\
\text { hospital admission appreciably }\end{array}$ \\
\hline MacLaren & 1993 & London UK & Head injured & $\begin{array}{l}\text { Fewer head injured patients were discharged from } A \& E \text { when the department's } \\
\text { SSW was available }\end{array}$ \\
\hline Hodgkinson & 1994 & Brisbane Australia & Drug overdose & Most overdosed patients can be safely managed on an observation unit \\
\hline Ward & 1991 & Mississippi USA & Pyelonephritis & Effective outpatient treatment is possible after brief period on observation ward \\
\hline Israel & 1991 & Texas USA & Pyelonephritis & Treatment for selected patients can be initiated on an observation unit \\
\hline Henneman & 1989 & Torrance USA & Abdominal trauma & $\begin{array}{l}\text { Patients with negative diagnostic peritoneal lavage can be managed safely and } \\
\text { cost-effectively on the observation unit }\end{array}$ \\
\hline Saunders & 1988 & Denver USA & Alcoholic pancreatitis & $\begin{array}{l}\text { Length of stay did not differ between patients on observation unit and those } \\
\text { admitted directly to hospital }\end{array}$ \\
\hline Ramaiah & 1987 & Clywd UK & Self injury/assault & The SSW is the ideal place for self injured or assaulted patients \\
\hline Ammons & 1986 & USA & Thoracic trauma & $\begin{array}{l}\text { Stable patients with normal chest } x \text { ray can be managed safely on the } \\
\text { observation unit }\end{array}$ \\
\hline Harrop & 1985 & Newport UK & Elderly & The SSW can be used for rapid social and physical rehabilitation \\
\hline Conrad & 1984 & Denver USA & Trauma & $\begin{array}{l}\text { An observation unit presents a viable, safe and cost-effective alternative for } \\
\text { selected trauma patients }\end{array}$ \\
\hline
\end{tabular}


patients saved $£ 45000$ per year, mainly by reducing psychiatric referrals. From the United States, Farrell ${ }^{40}$ estimated that a six bedded observation ward in his community hospital emergency department saved 1.7 hospital admissions per day with annual cost savings of $\$ 240000$. Conrad et $a l,{ }^{37}$ studying trauma victims, estimated that reduced length of stay produced an observation unit admission cost of $\$ 75$, compared with $\$ 147$ for a formal hospital admission, while Henneman et $a l^{32}$ estimated that managing 225 abdominal trauma victims with negative diagnostic peritoneal lavage on an observation unit resulted in potential savings of $\$ 51329$. Another study from the United States ${ }^{41}$ of 193 patients amenable to either acute hospital or observation unit care showed that while observation unit admission produced overall cost savings it could also paradoxically produce reduced profits for the hospital and hence be a disincentive to observation unit admission.

Overall these studies suggest that cost savings can be made by using short stay beds, although this effect may be reduced by producing a more cautious approach to direct discharge from the department. In risk management terms this may be appropriate, but improved safety related to the presence of short stay wards has yet to be shown.

Finally, the emergency department chest pain unit is a concept that has developed in the United States ${ }^{42}$ and has been found to be a safe and cost-effective means of caring for the patient with chest pain but low risk of myocardial ischaemia. ${ }^{434}$ This potential function of the short stay ward does not appear to have been explored yet in the United Kingdom.

Our survey shows that medical input largely reflects the BAEM guidelines that the ward should be under the direct control of the A\&E consultant, while middle grade or senior house officer A\&E staff provide immediate medical supervision. In practice the casemix of short stay wards will reflect the interests of the medical staff involved. Specialised areas of care, such as hand injuries, soft tissue infections, and self poisoning, may reflect a specialist interest in the department concerned. However, as higher specialist training in $A \& E$ develops it would be reasonable to expect a more universal definition of what cases are suitable for an $A \& E$ short stay ward to form. In this respect it is of concern that guidelines for higher specialist training ${ }^{45}$ contain few recommendations regarding training in the care of short stay patients. Any consultant expected to manage a short stay ward should have received training in this area. This deficiency should be addressed if we are to claim that $A \& E$ consultants are the ideal staff to run these facilities.

Admission rates in this survey are highly variable and reflect variability in the way beds are used and admissions defined. Some departments make very heavy use of beds by admitting patients for stays of only a few hours, while others have great difficulty preventing beds being taken by other specialties.

It would be naive to expect short stay provision to depend entirely upon formal evidence of clinical value. Political and economic interests will continue to play a major role in determining what facilities are available. While randomised controlled trials may be impractical, the present situation does allow potential for performing comparative studies similar to those mentioned above. ${ }^{26-28} 3339$ These could be used to establish evidence based guidelines for resource allocation and casemix of admissions.

\section{CONCLUSION}

The provision of short stay facilities in the United Kingdom in terms of bed numbers, admission numbers, and casemix is highly variable, although medical cover is comprehensive. Studies of short stay facilities have shown many well functioning units with considerable enthusiastic support, but objective comparisons with other methods of care are hard to find. If $A \& E$ short stay wards are to be developed beyond the requirements of managerial expediency then $A \& E$ specialists must take the lead in defining standards of training and provision and researching the clinical and economic data to justify their use.

1 Nuffield Provincial Hospitals Trust. Casualty services and their setting: a study in medical care. Oxford: Oxford University Press, 1960.

2 Standing Medical Advisory Committee CHSC. Accident and emergency services (The Platt Report). London: HMSO, 1962

3 Lewin W. Medical staffing and accident and emergency services. London: Joint Consultants Committee, 1978.

4 Accident and emergency services. BMJ 1979;ii:837-9.

5 British Association for Accident and Emergency Medicine Clinical Services Committee. Recommendations for accident and emergency wards. London: BAEM, 1989.

6 British Association for Accident and Emergency Medicine. Directory 1996. London: BAEM, 1996.

7 Rutherford WH. Accident and emergency medicine, 2nd ed. London: Longman, 1989:14.

8 Beattie TF, Ferguson J, Moir PA. Short-stay facilities in accident and emergency departments for children. Arch Emerg Med, 1993; 10: 177-180.

9 Klein BL, Patterson M. Observation unit management of paediatric emergencies. Emerg Med Clin North Am 1991; 9:669-76.

10 Rainer TH, Swann IJ, Crawford R. Critical analysis of an accident and emergency ward. J Accid Emerg Med 1996;13:325-9.

11 Jones A, O'Driscoll $\mathrm{K}$, Luke $\mathrm{L} \mathrm{C}$. Head injuries and the observation ward [letter]. J Accid Emerg Med 1995;12: $160-1$

12 Maimaris C, Kirby N. The impact of the observation ward on acute admissions at Guy's Hospital. Health Trends 1991;23:33-5.

13 Jelinek GA, Galvin GM. Observation wards in Australian hospitals. Med J Aust 1989;151:80-3.

14 Clancy MJ. A one year prospective study of the use of an observation ward by an accident and emergency department. Br J Accid Emerg Med 1989;Sept:9-10.

15 Driscoll P, Bryce G. The use of short stay wards. survey of 1000 admissions. Health Bull 1987;45:294-302.

16 Gabbay J, Mason E. Assessing a short stay ward. Senior Nurse 1987;6:20-2.

17 Neville L, Rowland RS. Short stay unit solves emergency overcrowding. Dimensions Health Serv 1983;60:26-7.

18 Ramaiah RS, Jones DT, Pal AK. Combined short-stay/day surgery/ investigation unit in a district general hospital. surgery/ investigation 1 . 19 Dallos V, Mouzas GL. An evaluation of the functions of the department. BMJ 1981;282:37-40.

20 Morgan WJ. Functions of the observation ward in the accident and emergency department [letter]. BMJ 1981;282 398.

21 Bobzien WF. The observation-holding area: a prospective study. J Am Coll Emerg Physicians 1979;8:508-12.

22 Diamond NJ, Schofferman JA, Elliott JW. Evaluation of an emergency department observation ward. J Am Coll Emerg Physicians 1976;5:29-31.

23 Landers GA, Waeckerle JF, McNabey WK. Observation ward utilization. J Am Coll Emerg Physicians 1975;4: 123-5.

24 Taubenhaus LJ, Robilotti GD. The holding area: new arm of the ED. J Am Coll Emerg Physicians 1972;1:15-19. 
25 Ryan J, Clemmett S, Perez-Avila C. Managing patients with deliberate self-harm admitted to an accident and emergency
$31-3$.

26 Brown SR, Raine C, Robertson CE, Swann IJ. Management of minor head injuries in the accident and emergency department: the effect of an observation ward. J Accid Emerg Med 1994;11:144-8.

27 Brillman JC, Tandberg D. Observation unit impact on ED admission for asthma. Am J Emerg Med 1994;12:11-14.

28 MacLaren RE, Ghoorahoo HI, Kirby NG. Use of an accident and emergency department observation ward in the management of head injury. Br J Surg 1993;80:215-7.

29 Hodgkinson DW, Jellett LB, Ashby RH. A review of the management of oral drug overdose in the Accident and Emergency Department of the Royal Brisbane Hospital. Arch Emerg Med 1991;8:8-16.

30 Ward G, Jorden RC, Severance HW. Treatment of pyelonephritis in an observation unit. Ann Emerg Med 1991;20: 258-61.

31 Israel RS, Lowenstein SR, Marx JA, Koziol-McLain J, Svoboda $\mathrm{L}$, Ranniger $\mathrm{S}$. Management of acute pyelonephritis in an emergency depa

32 Henneman PL, Marx JA, Cantrill SC, Mitchell M. The use of an emergency department observation unit in the management of abdominal trauma. Ann Emerg Med 1989;18 647-50.

33 Saunders CE, Gentile DA. Treatment of mild exacerbations of recurrent alcoholic pancreatitis in an emergency department observation unit. South Med J 1988;81:317-20.

34 Ramaiah RS, Pal AK. The work load and cost implications of patients with self injury/assault in a short stay ward. Br J Accid Emerg Med 1987; Sept:5-6.

35 Ammons MA, Moore EE, Rosen P. Role of the observation unit in the management of thoracic trauma. J Emerg Med $1986 ; 4: 279-82$.
36 Harrop SN, Morgan WJ. Emergency care of the elderly in the short stay ward of the accident and emergency department. Arch Emerg Med 1985;2:141-7.

37 Conrad L, Markovchick V, Mitchiner J, Cantrill SV. The role of an emergency department observation unit in the management of trauma patients. J Emerg Med 1984;2: 325-33.

38 Brown AFT, Wilkes GJ, Myers CT. Use of an accident and emergency department observation ward in the management of head injury [letter]. Br J Surg 1993;80:1079.

39 Hadden DSM, Dearden CH, Rocke LG. Short stay observation patients: general wards are inappropriate. J Accid Emerg Med 1996;13:163-5.

40 Farrell RG. Use of an observation ward in a community hospital. Ann Emerg Med 1982;11:353-7.

41 Graff LG, Radford MJ, Gunning MA, Werne CS. The observable patient in the DRG era. Am J Emerg Med 1988;6:93-103.

42 Graff L, Joseph T, Andelman R, Bahr R, DeHart D, Espinosa J, et al. American College of Emergency Physicians information paper: chest pain units in emergency departments - a report from the short-term observation services section. Am J Cardiol 1995;76:1036-9.

43 Deleon AC, Farmer CA, King G, Manternach J, Ritter D. Chest pain evaluation unit: a cost-effective approach for ruling out acute myocardial infarction. South Med J 1989; 82:1083-9.

44 Gaspoz J, Lee TH, Weinstein MC, Cook EF, Goldman P, Komaroff $\mathrm{AL}$, et al. Cost-effectiveness of a new short-stay unit to "rule out" acute myocardial infarction in low-risk patients. J Am Coll Cordial 1994;24:1249-59.

45 The Board of the Faculty of Accident and Emergency Medicine. Guidelines for specialist training in accident and emergency medicine. London: BMJ Publishing Group, 1996.

\section{Faculty of Accident and Emergency Medicine}

\section{Consultant appointments, January-April 1997}

\author{
Mr K A Bizos \\ Mr M J Stuart \\ Mr S Bhattacharyya \\ Mr H Dardouri \\ Ms J Nancarrow \\ Mr J McKeever \\ Mr M Morris
}

Stoke Mandeville Hospital, Aylesbury

North Manchester Healthcare

Burnley Healthcare

Blackburn/Ribble Health

Blackburn/Ribble Health

Greenwich Healthcare

Warwick Hospital

\section{Consultant appointments April-September 1997}

\author{
Ms M Dudek \\ Ms M Grocott \\ Mr A I Jones \\ Mr A MacNamara \\ Mr D McCreadie \\ Mr S J McGovern \\ Mr A L Pinto \\ Mr A Soorma \\ Ms C Taylor \\ Mr M Zahie
}

Royal Berkshire Hospital

Worthing Hospital

North Tyneside Healthcare

Birmingham Heartlands

New Cross Hospital, Wolverhampton

Craigavon Area Hospital

Wigan and Leigh Health

MidKent Healthcare Trust

Queen Mary's Sidcup

New Cross Hospital, Wolverhampton 